\title{
Reliability and Validity of the CAP for Computer Access Assessment of Persons with Physical Disabilities
}

\author{
Dong-Hoon Jeong \\ Department of Rehabilitation Technology, Korea Nazarene University, Cheonan, Korea
}

Purpose: The purpose of this study was to develop a computer access assessment tool for persons with physical disabilities and to evaluate reliability and validity.

Methods: We developed a computerized Computer access Assessment Program (CAP) through many kinds of literature review and tools analysis for evaluation of computer access, task analysis of fundamental input devices operation and expert review. The CAP data were obtained from 105 normal university students and 16 students with physical disabilities. The test items of CAP are composed of four timed mouse tasks, four timed keyboard tasks, and a timed scanning task. Thus, the software measures user performance in skills needed for computer interaction, such as keyboard and pointer use, navigating through menus, and scanning. To determine the validity of these measurements, we compared data on CAP reports to a Compass report. Compass software allows an evaluator for assessment of an individual's computer input skills.

Results: Results of this study showed that the CAP had high internal consistency, reliability of test-retest, concurrent validity, and convergent validity.

Conclusion: Therefore, the CAP is appropriate for evaluation and determination of computer access skill of persons with physical disabilities. It is possible to get clear quantitative data on performance when providing computer access services if you can use the CAP data. Using this quantitative evidence, insights can be gained into the specific nature of any difficulties experienced by persons with physical disabilities and find wise solutions.

Keywords: Computer access, CAP, Physical disabilities

\section{서 론}

정보통신 기술의 발전과 인터넷 사용이 장애인에게 많은 긍정적 기 회를 제공하면서 컴퓨터는 일상에서 중요한 도구가 되었고, 장애인 이 많은 기능적 활동을 수행할 수 있도록 도움을 준다. ${ }^{1,2}$ 그러나장애 인은 장애의 특성에 따라 컴퓨터 사용에 제약을 받으며, 특히 지체 및 뇌병변 장애인은 주로 운동장애를 동반하여 운동기능, 조작기능, 도달기능, 지지기능 등 상지 관련 기능의 문제로 인해 컴퓨터 사용에 어려움이 있다..$^{3-5}$ 따라서 일반 키보드나 마우스 사용이 어려운 지체 장애인을 위해 확대키보드와 미니키보드, 조이스틱, 안구조절 마우 스 등 다양한 대체입력장치들이 개발되었고, 재활치료사와 특수교
사 등 다양한 재활전문가들이 이러한 컴퓨터 접근기술(computer access technology, CAT) 서비스를 제공하고 있다. ${ }^{6}$

성공적인 CAT 서비스를 위해서는 사용자의 기능수준과 컴퓨터 사용 시의 문제점을 증명해야 하고, 문제를 해결할 수 있는 가장 적합 한 입력기기를 선택해야 한다. 또한 시스템을 적합하게 사용할 수 있 도록 사용자 훈련과 인터페이스 적합성의 유지를 위한 지속적인 사 후관리가 요구된다. 이들 문제 중 어느 하나라도 성공적으로 해결되 지 못한다면 CAT 서비스에 소요된 인적, 물적 자원의 낭비와 장애인 의 컴퓨터 사용 및 테크놀로지 사용을 포기하는 원인이 된다. 그러 나 보고된 바에 의하면 대부분 이러한 문제들을 해결하지 못하고 있 으며, 컴퓨터를 소유하고 있는 많은 장애인들이 CAT의 도움을 받지
Received January 13, 2015 Received February 2, 2015

Accepted February 9, 2015

Corresponding author Dong-Hoon Jeong

E-mail dhjeong@kornu.ac.kr
Copylight (C)2015 The Korean Society of Physical Therapy

This is an Open Access article distribute under the terms of the Creative Commons Attribution Non-commercial License (Http:// creativecommons.org/license/by-nc/3.o.) which permits unrestricted non-commercial use, distribution, and reproduction in any medium, provided the original work is properly cited.

- This research was supported by the Korea Nazarene University research grants 2014. 
못하고 있는 것으로 조사되었다. ${ }^{8}$ 보편적인 키보드와 마우스를 대체 하는 다양한 제품들이 개발되어 판매되고 있는 상황에서 사용자는 자신에게 적합한 대체입력장치를 선택하기가 더욱 어려워졌다. 한 두 번의 시험사용 후에 제품을 구입하게 되면 나중에 자신의 필요와 요 구에 맞지 않아 사용을 포기하고, 컴퓨터 접근성 효율은 떨어지지만 어쩔 수 없이 일반 키보드와마우스를 통해 컴퓨터를 사용하고 있는 실정이다. 이러한 컴퓨터 접근성에 대한 문제를 해결하기 위해 다양 한 방법들이 사용되고 있으나 각 개인의 특성을 고려한 CAT 선택은 무엇보다도 정확하고 체계적인 평가가 선행되어야 한다. ${ }^{9}$

그동안 컴퓨터 접근성 평가는 전문가에 의한 임상관찰법이 가장 보편적으로 사용되어 왔다. 그러나 정확하고 객관적인 체계가 부족 하여 적합한 CAT를 선정하기 어렵고, 전문가의 경험과 숙련도에 의 해 평가 결과가 좌우되는 문제점도 지적되고 있다. 최근에는 임상관 찰법이나 매뉴얼 평가도구의 한계를 극복하고 정량적인 데이터를 통 해 컴퓨터 접근성의 문제를 증명하며, 개인에게 가장 적합한 CAT를 추천할 수 있도록 컴퓨터 기반 평가도구들이 개발되고 있다. 그중 Compass 프로그램은 속도 및 정확도 측정의 정밀성은 물론 광범위 한 사용성 평가가 수행되어 사용 편리성이 입증된 컴퓨터 접근성 평 가 도구다. ${ }^{10}$ 국내에서는 Physical Characteristics Assessment 등 외국의 매뉴얼 평가도구를 번역하여 사용하거나 이를 참조한 매뉴얼 평가도 구 개발 사례가 있었으나 임상에서 사용되지는 못하였다." 다행히 최 근 국내에서도 컴퓨터 기반 평가 프로그램의 개발과 도입 필요성을 인식하여 몇몇 연구가 진행되었다.12,13 그러나 공통적으로 국외 평가 프로그램의 핵심 내용만을 설계에 반영하여 사용자의 요구에 부합 하는 기능 검사를 맞춤 계획 할 수 없거나 문자입력 검사를 타 프로 그램과 연동해야 하는 등 지체장애인의 컴퓨터 접근성 평가의 필수 항목이 반영되지 못한 문제점이 있었다. 또한 장애인을 대상으로 평 가도구의 신뢰도와 타당도 검증이 이루어지지 않아 임상에서 사용 되지 못하고 있다.

컴퓨터 정보화 사회에서 치료사는 흔히 클라이언트의 컴퓨터 접 근성을 증진시키는 전문가로 추천되어 왔지만 실제로는 다양한 어려 움에 직면하게 된다. ${ }^{2}$ 물리치료사는 컴퓨터 대체입력장치 같은 일상
생활보조기기를 처방하고 사용할 수 있도록 훈련시킬 수 있는 가장 이상적인 위치에 있으나 임상에서의 활용 실태와 인식은 매우 저조 한 것으로 조사되고 있다. ${ }^{4}$ 무수히 많이 개발되어 출시되는 컴퓨터 보조기기를 올바르게 선택하고 사용할 수 있도록 하기 위해서는 무 엇보다도 정확하고 객관적인 평가 시스템의 확보가 선결되어야 한다.

본 연구는 정확하고 체계적인 평가를 통해 지체장애인의 컴퓨터 접근성 증진을 돕는 컴퓨터 기반의 Computer access Assessment Pro$\operatorname{gram}(\mathrm{CAP})$ 을 설계 구현하고, 신뢰도와 타당도를 검증하고자 실시하 였다.

\section{연구방법}

\section{1. 연구 대상자}

연구에 참여한 대상자는 마우스와 키보드 등 컴퓨터 입력장치 사용 에 문제가 없는 20 대의 신체 건강한 대학생 105 명이었다. 그리고 뇌병 변 또는 지체장애로 진단받은 16 명의 장애학생이 참여했으며, 이들 은 모두 컴퓨터를 사용하고 있고 정도의 차이는 있으나 운동장애로 인해 컴퓨터 입력장치 사용에 제약이 있는 대상자로 구성하였다. 또 한 평가 내용을 보고 이해할 수 있으며 평가 시 사용하는 포인팅기기 와 키보드를 사용할 수 있는 학생이었다. 필요에 따라 손목지지대와 같은 개인 소유의 액세서리를 사용하였으나 모든 대상자가 일반 키 보드와 마우스를 사용하여 과제를 수행하였다. 장애학생의 과제수 행에 영향을 미칠 수 있는 근 긴장도는 Modified Ashworh Scale을 통 해 평가하여 G0에서 G1+ 등급의 학생들로 선정하였고, 손 기능은 manual ability classification system (MACS) I에서 III 등급의 학생들을 선정하였다. 실험을 실시하기 전 모든 대상자에게 실험 내용과 과정, 연구 목적에 대해 설명하였고, 실험 참여에 대한 동의를 구하였다. 대 상자의 일반적 특성은 Table 1과같다.

\section{2. 연구 도구}

1) CAP

$\mathrm{CAP}$ 은 평가를 수행하는 동안 자동적으로 속도와 정확도 등을 측정

Table 1. General characteristics of participants

\begin{tabular}{|c|c|c|c|c|c|}
\hline \multicolumn{2}{|l|}{ Domain (university students) } & \multirow[t]{2}{*}{ Frequency (\%) } & \multicolumn{2}{|c|}{ Domain (disability students) } & \multirow[t]{2}{*}{ Frequency (\%) } \\
\hline Age (year) & $21.05 \pm 1.29$ & & Age (year) & $22.62 \pm 5.13$ & \\
\hline \multirow[t]{2}{*}{ Gender } & Male & $57(54.3)$ & Gender & Male & $9(56.3)$ \\
\hline & Female & $48(45.7)$ & & Female & $7(43.7)$ \\
\hline \multirow[t]{3}{*}{ Years of computer use (year) } & $<5$ & $0(0)$ & Years of computer use (year) & $<5$ & $5(31.3)$ \\
\hline & $5-10$ & $18(17.1)$ & & $5-10$ & $9(56.2)$ \\
\hline & $\geq 10$ & 87 (82.9) & & $\geq 10$ & $2(12.5)$ \\
\hline Total & & $105(100)$ & Total & & $16(100)$ \\
\hline
\end{tabular}




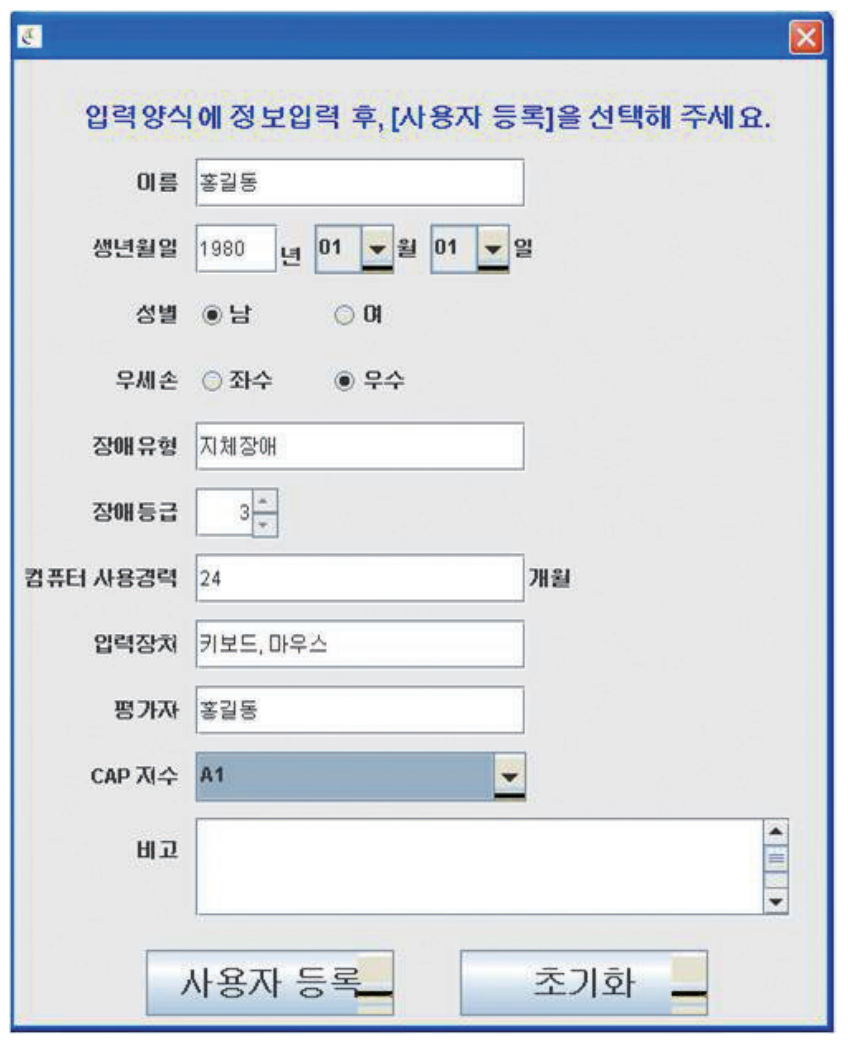

Figure 1. 'User registration' window.

하여 기록하고, 이해하기 쉽게 정량적 데이터를 요약 리포트 할 뿐만 아니라 상세내역을 제공하여 두 개 이상의 데이터를 비교 분석할 수 있는 기능이 제공된다. 프로그램은 사용자 관리, 환경설정, 테스트 수 행, 리포트 관리 등 네 가지의 기능구조로 되어 있다. 사용자 관리에 서 신규 사용자 등록 및 기존 사용자 관리가 가능하다(Figure 1). 사용 자 정보입력이 끝나고 사용자 등록'을 클릭하면 '테스트 항목 선택' 창 이 나타나고, 필요한 테스트 항목을 추가하거나 제거할 수 있다. 테스 트 항목 중 마우스 사용기술은 클릭, 더블클릭, 드래그 \& 드롭으로 구 성되며, 키보드 사용기술은 한글 및 영문으로 제시되는 문자, 단어, 문장의 입력 정확도와 반응시간을 측정한다. 스캐닝은 스위치, 마우 스, 키보드 등과 같은 입력기기의 스캐닝 수행 능력을 평가하는 것으 로, 화면에 제시되는 문자, 기호 등을 보고 해당하는 문자, 기호 등에 커서가 활성화 되었을 때 선택하면 된다. 메뉴 사용기술은 창에 제시 되는 메뉴 항목을 메뉴 바에서 정확하게 찾아 선택할 수 있는지를 평 가한다. 테스트를 선택하면 '선택 테스트 목록'에 제시되고, 하단의 '저장하기'를 클릭하면 '테스트 목록' 창으로 전환된다(Figure 2). '테스 트 목록'창을 보면, '(1) 테스트 목록 메인 창' 옆에 '(2) 테스트 툴 바'가 있다. 현재 상태에서는 ‘항목추가만 활성화되어 있으나 테스트 목록 에서 각 테스트를 선택하면 '설정관리', '평가수행', '항목제거' 등이 활 성화되고, '설정관리'를 클릭하면 개별 테스트마다 환경설정을 위한

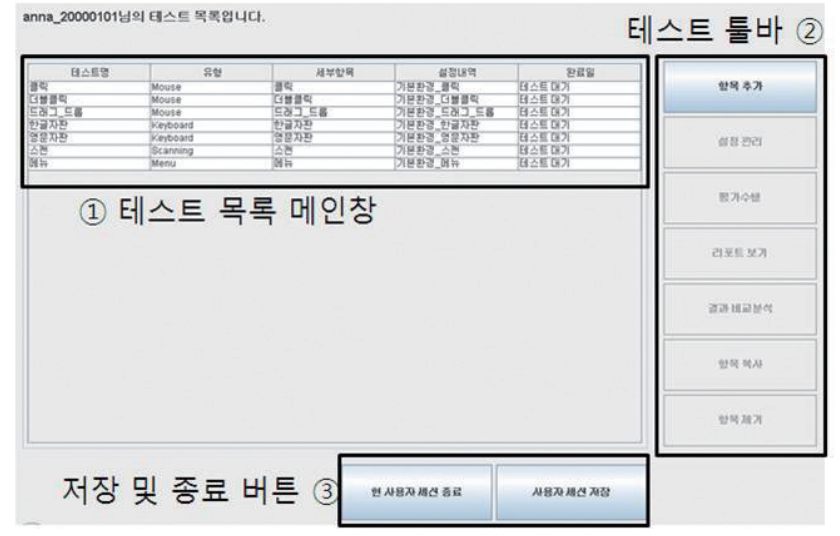

Figure 2. 'Test lists' window.

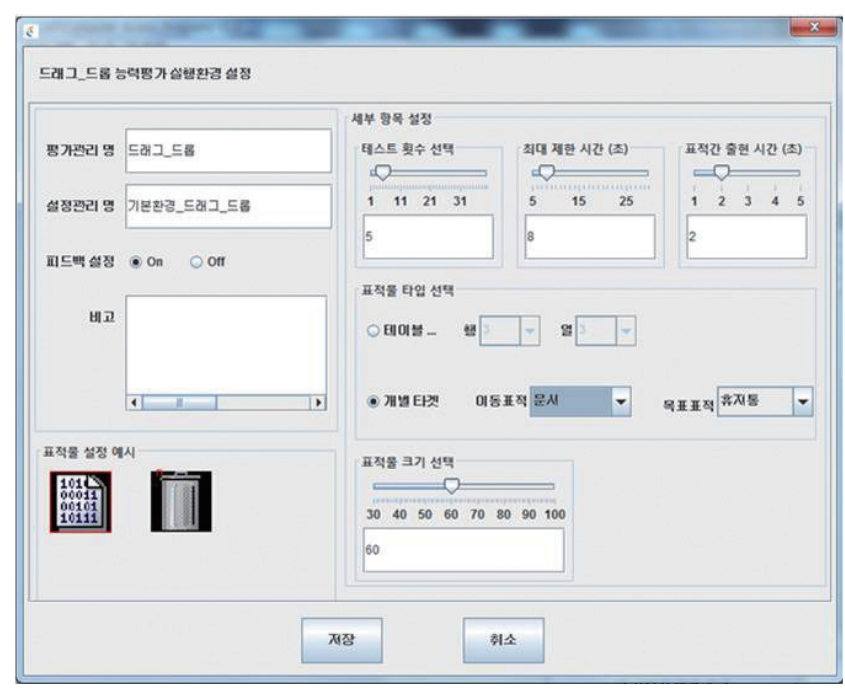

Figure 3. 'Set up for drag/drop test' window.

창이 나타난다. 드래그/드롭을 위한 '환경설정' 창을 보면, 좌측 상단 의 '평가 관리명'은 현재 진행하는 테스트의 이름을 평가자가 원하는 이름으로 변경할 수 있고, 추후 테스트 결과를 비교분석할 때 테스 트 이름별로 구분이 가능하다. 설정 관리명'은 같은 드래그/드롭 테스 트일지라도 환경설정을 다르게 구성하였다면, 이름을 변경해서 저장 하여 추후 테스트 결과를 비교분석할 때 환경설정별 구분이 가능하 도록 하였다. '피드백 설정'은 테스트 중 사용자의 정 반응과 오 반응 을 구별하여 청각 또는 시각적 피드백을 제공하는 기능을 한다. 따라 서 입력장치 사용훈련 시 청각 또는 시각적 피드백을 통해 동기부여 및 훈련 효과의 증진을 기대할 수 있다. 화면 좌측의 세부 항목 설정' 은 테스트 횟수와 과제수행을 위한 제한시간, 표적 간 출현시간 등을 대상자의 수준에 맞게 설정할 수 있다(Figure 3).

환경설정이 완료되면 저장하고 테스트 툴 바의 ‘평가수행' 버튼을 누르면 테스트가 시작된다. 예를 들어 클릭 테스트의 경우 화면에 표 적물이 나타나면 마우스 등의 포인팅기기를 사용하여 정확하게 커 


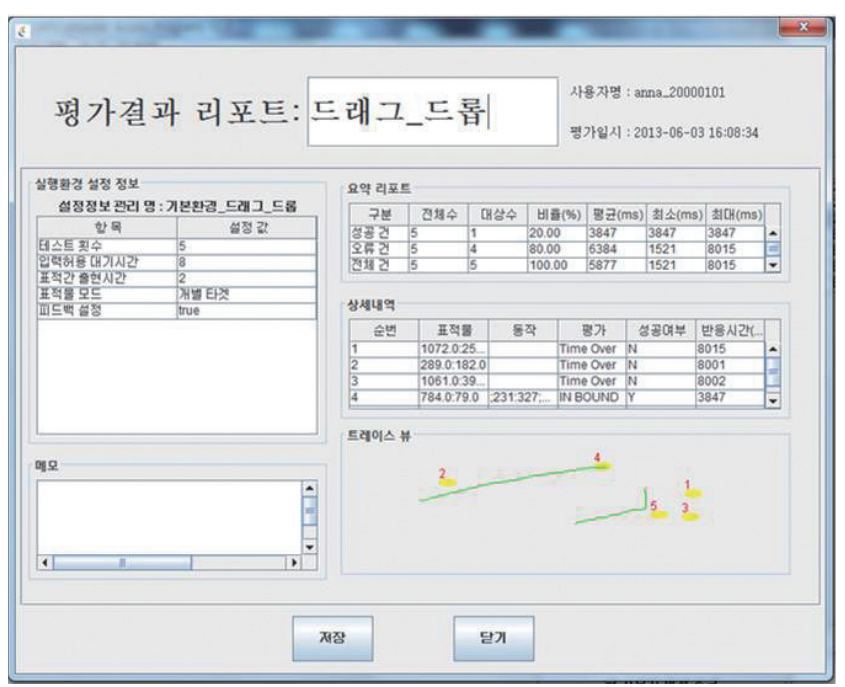

Figure 4. 'Detailed outcome report for drag/drop test' window.

서를 이동시키고 클릭 버튼을 누르면 된다. 표적물을 정확하게 클릭 하거나 표적물이 아닌 위치에서 클릭하게 되면 각각을 정 반응과 오 반응으로 인식하고 다음 표적물이 제시된다. 또한 환경설정에서 정 한 최대 제한시간이 초과해도 다음 표적물이 자동으로 제시된다. 테 스트를 중도에 중지하거나 종료해야 하는 경우에는 좌측 상단에 있 는 '테스트 종료' 버튼을 누르면 ‘테스트 목록' 창으로 되돌아간다.

테스트 툴 바의 '리포트 보기를 클릭하면 실행한 테스트의 결과를 확인할 수 있다(Figure 4). 드래그/드롭 테스트의 평가결과 리포트를 보면, 화면 좌측의 '실행환경 설정 정보'를 통해 환경설정에 관한 정보 를 한 눈에 볼 수 있고, '메모'는 테스트 수행 중 특이사항 등을 기재할 수 있다. 우측에 제시되는 '요약 리포트'와 상세내역'은 과제수행의 성 공 여부, 소요된 최대 시간과 최소 시간, 평균 시간, 정확도 등에 대한 정량적 데이터를 제공한다. '트레이스 뷰'는 표적물이 나타난 위치와 커서를 움직여 드래그/드롭까지의 위치관계 궤적을 나타내고 있다. 따라서 '요약 리포트'와 '상세내역'에서 제공하는 정량적 데이터와 함 께 실질적인 커서의 이동 궤적을 확인하다 보면 과제수행 시 문제가 되는 원인을 알 수 있다. 예를 들면, 불수의 운동으로 커서의 이동 초 기나 중기에 이동 궤적이 벗어나는지 또는 표적물에 커서를 정확하 게 위치시키는 데 어려움이 있는지를 판단할 수 있어, 이들 특성을 고 려한 최적의 입력장치 선택이 가능하다. '요약 리포트'와 상세내역'의 데이터는 복사하여 엑셀이나 한글/워드에 데이터 업로드 할 수 있어 이차적 통계분석이나 자료 활용이 용이하다. 그리고 테스트 툴 바의 '결과 비교분석' 버튼을 클릭하면 2개 이상의 테스트 결과를 그래프 로 비교 분석하여 제시한다. 평가 대상자의 회기 당 반응속도를 그래 프로 제시하고 목표치를 설정하여 자신의 현재 수준과의 비교가 가 능하도록 하여 컴퓨터 접근성 수준의 변화 추이와 훈련 효과 등을 쉽
게 확인할수 있도록 해준다.

\section{2) Compass 프로그램}

Compass는 공인타당도 비교를 위해 사용하였으며, 문자입력은 물론 마우스 또는 포인터, 그리고 스위치 사용 같은 다양한 종류의 컴퓨터 상호작용 기술을 측정할 수 있어 널리 사용되고 있다. Compass는 속 도 및 정확도 측정의 정밀성 검사는 물론 광범위한 사용성 평가가수 행되어 사용편리성도 입증되었다. 재검사 신뢰도는 모든 항목에서 0.80 이상이었고, 프로그램 구성의 일관성을 측정하는 Cronbach's a 값은 0.77 로 나타나 전반적인 컴퓨터 사용기술을 실질적으로 측정할 수 있는 도구다. ${ }^{5,15}$ 검사항목은 포인팅, 스캐닝, 문자입력의 3 가지와 세부 항목 8 가지의 기능을 검사한다. 스캐닝은 제시되는 문자와 동일 한 문자를 행렬 상자에서 스캐닝 방식으로 선택하는 것으로, 중증장 애인이 스위치 사용을 통한 컴퓨터 접근성을 검사하는 것이다. 본 연 구에서는 포인팅의 3 가지 항목(클릭, 드래그, 메뉴)과 스캐닝, 그리고 영어 문자입력(단어, 문장) 등 총 6 가지 항목을 검사하였다. 환경설정 은 개별 장애학생의 운동 능력과 과제 수행력에 기초하여 과제수행 제한시간, 타깃의 크기와 형태, 거리를 조정하여 CAP의 환경설정과 동일하거나 유사한 조건에서 실험하였다.

\section{3. 검사절차}

\section{1) 검사 기간 및 환경}

검사 기간은 2013년 9월부터 2014년 4월까지 7개월 동안 실시하였으 며, 검사는 보조공학을 전공한 작업치료사로, 컴퓨터 접근성 관련 실무경력을 갖춘 전문가 1 인이 실시하였다. 검사장소는 측정 결과에 영향을 주는 환경 변화를 최소화하기 위해 컴퓨터 워크스테이션이 갖추어진 실습실에서 진행하였다. 높낮이 조절이 가능한 컴퓨터 테 이블과 의자를 사용하여 대상자의 신체 크기에 맞게 자유롭게 조정 하였고, 검사에 사용된 입력장치는 일반 키보드와 마우스를 사용하 였다.

\section{2) $\mathrm{CAP}$ 검사항목 구성 및 환경설정}

$\mathrm{CAP}$ 의 검사항목은 포인팅 4 가지 항목(클릭, 더블클릭, 드래그/드롭, 메뉴 찾기), 스캐닝, 그리고 문자입력 4가지 항목(한글 단어 및 문장입 력, 영어 단어 및 문장입력) 등 총 9가지로 구성하였고, 일반 대학생은 모든 항목을 검사하였으나 장애학생은 영어 문자입력(단어와 문장 입력) 검사는 실시하지 않았다. 포인팅 검사를 위한 환경설정은 모두 동일하게 테스트 횟수 12 회, 최대 제한시간 8초, 표적 간 출현시간 2 초, 표적물 이동경로 무작위, 표적물 크기 60으로 하였으며 청각적 피 드백을 제공하였다. 메뉴는 테스트 횟수 8 회, 최대 제한시간 8 초, 폰트 는 바탕체, 검정색, 크기 20으로 설정하였다. 스캐닝은 테스트 횟수 8 
회, 최대 제한 반복횟수 3 회, 표적 간 출현시간 2 초, 스캐닝 표적물 이 동시간은 행간 이동과 열 간 이동 모두 3 초로 설정하였다. 단어와 문 장입력의 폰트는 바탕체, 검정색, 크기 20으로 설정하였고, 표적 간 출 현시간은 2 초로 하였다. 그리고 단어입력의 경우 테스트 횟수는 8 회, 최대 제한시간은 20 초로 하였으며, 문장입력의 경우 테스트 횟수 4 회, 최대 제한시간은 60초로 설정하였다.

\section{4. 자료 분석}

CAP의 타당도와 신뢰도 검증을 위한 자료처리 및 분석은 SPSS 12.0 통계 패키지 프로그램을 사용하였다. 공인타당도 검증을 위해 Compass 프로그램과의 상관계수를 산출하였고, 수렴 타당도는 평가 항목 사이의 상관계수를 산출하였다. 그리고 검사-재검사 신뢰도 검 증을 위해 Pearson의 적률상관계수를 산출하였고, 내적 일관성 신뢰 도 검증을 위해 Cronbach's $\alpha$ 계수를 산출하였다.

\section{결 과}

\section{CAP의 공인 타당도 검증}

Compass 프로그램과의 상관계수를 산출한 결과, 본 연구에서 개발 한 CAP과 Compass는 전체적으로 유의한 정적 상관이 있는 것으로 나타났다 $(\mathrm{r}=0.42, \mathrm{p}<0.01)$. 하위 검사항목별로 살펴보면, 스캐닝이 $r=0.6$, 영어 문자입력은 $r=0.62$, 포인팅은 $r=0.43$ 으로 나타나 모두 통 계적으로 유의한 상관관계를 보였다 $(\mathrm{p}<0.01)$ (Table 2).

\section{CAP의 수렴타당도 검증}

$\mathrm{CAP}$ 의 수렴 타당도를 알아보기 위해 하위 검사항목 간의 상관계수 를 산출한 결과 $r=0.12$ 에서 $r=0.40$ 까지 나타났고, 하위 검사항목과

Table 2. Concurrent validity of the CAP with relevant areas of the Compass

\begin{tabular}{lcccc}
\hline & \multicolumn{3}{c}{ CAP } \\
\hline Compass & Pointing & Scanning & Text entry (English) & Total \\
& $0.43^{*}$ & $0.66^{*}$ & $0.62^{*}$ & $0.42^{*}$ \\
\hline
\end{tabular}

${ }^{*} p<0.01$.

Table 3. Convergent validity of the CAP

\begin{tabular}{lccccc}
\hline CAP & Pointing & Scanning & $\begin{array}{c}\text { Text entry } \\
\text { (Korean) }\end{array}$ & $\begin{array}{c}\text { Text entry } \\
\text { (English) }\end{array}$ & Total \\
\hline Pointing & 1.00 & & & & \\
Scanning & 0.04 & 1.00 & & & \\
Text entry (Korean) & 0.12 & 0.02 & 1.00 & & \\
Text entry (English) & 0.15 & 0.05 & $0.33^{*}$ & 1.00 & \\
Total & $0.21^{* *}$ & 0.18 & $0.40^{*}$ & $0.38^{*}$ & 1.00 \\
\hline
\end{tabular}

${ }^{*} p<0.01 ;{ }^{* *} p<0.05$
$\mathrm{CAP}$ 전체와의 상관계수는 포인팅 $\mathrm{r}=0.21(\mathrm{p}<0.05)$, 한글 문자입력 $\mathrm{r}=0.40(\mathrm{p}<0.01)$, 영어 문자입력 $\mathrm{r}=0.38(\mathrm{p}<0.01)$ 로 나타나 높은 수준 의 타당도를 보였다(Table 3).

\section{CAP의 검사-재검사 신뢰도 검증}

$\mathrm{CAP}$ 의 검사-재검사 신뢰도를 알아보기 위해 2 주 간격으로 실시한 검 사-재검사 자료의 Pearson 적률상관계수를 산출한 결과 전체적으로 일반 대학생 $r=0.82$, 지체장애학생 $r=0.84$ 로 나타나 모두 높은 상관 관계를 보였다 $(\mathrm{p}<0.01)$. 일반 대학생의 하위 검사항목별 신뢰도 계수 를 살펴보면, 포인팅 $r=0.89$, 스캐닝 $r=0.73$, 한글 문자입력 $r=0.79$, 영 어 문자입력 $r=0.69$ 로 나타나 포인팅과 한글 문자입력, 그리고 스캐 닝에서 비교적 높은 재검사 신뢰도를 보였다. 지체장애학생의 하위 검사항목별 신뢰도 계수는 포인팅 $r=0.85$, 스캐닝 $r=0.68$, 한글 문자 입력 $\mathrm{r}=0.89$ 로 나타나 한글 문자입력과 포인팅 과제수행에서의 재검 사 신뢰도가 높게 나타났다(Table 4).

\section{CAP의 내적 일관성 신뢰도 검증}

$\mathrm{CAP}$ 의 내적 일관성 신뢰도를 알아보기 위해 Cronbach's a 값을 산출 한 결과, 신뢰도 계수는 전체적으로 일반 대학생 0.63 , 지체장애학생 0.79 로 나타나 중등도의 높은 신뢰도 수준을 보였다. 일반 대학생의 하위 검사항목별 Cronbach's a 값을 살펴보면, 포인팅 0.84 , 스캐닝 0.38 , 문자입력 0.65 로 나타나 포인팅과 문자입력에서 높은 신뢰도를 보였다. 지체장애학생의 하위 검사항목별 Cronbach's $\alpha$ 값을 살펴보 면, 포인팅 0.75 , 스캐닝 0.65 , 문자입력 0.86 으로 나타나 전체적으로 모 든 항목에서 신뢰도가 높게 나타났다(Table 5).

Table 4. Test-retest reliability of the CAP

\begin{tabular}{lcc}
\hline \multirow{2}{*}{ Test items } & \multicolumn{2}{c}{ Test-retest reliability correlation coefficient } \\
\cline { 2 - 3 } & University students & Students with physical disabilities \\
\hline Pointing & 0.89 & 0.85 \\
Scanning & 0.73 & 0.68 \\
Text entry (Korean) & 0.79 & 0.89 \\
Text entry (English) & 0.69 & - \\
Total & 0.82 & 0.86 \\
\hline
\end{tabular}

Table 5. Internal consistency of the CAP

\begin{tabular}{|c|c|c|c|c|}
\hline \multirow{2}{*}{ Test items } & \multicolumn{2}{|c|}{ University students } & \multicolumn{2}{|c|}{$\begin{array}{c}\text { Students with } \\
\text { physical disabilities }\end{array}$} \\
\hline & Number of items & Cronbach' $\alpha$ & Number of items & Cronbach' $\alpha$ \\
\hline Pointing & 4 & 0.84 & 4 & 0.75 \\
\hline Scanning & 1 & 0.38 & 1 & 0.65 \\
\hline Text entry & 4 & 0.65 & 2 & 0.86 \\
\hline Total & 9 & 0.63 & 7 & 0.79 \\
\hline
\end{tabular}




\section{고 찰}

그동안 외국의 평가도구를 참고하여 베타 버전의 컴퓨터 접근성 평가 도구 개발이 시도되었으나 타당도와 신뢰도 검증이 이루어지지 못하 였다. 그리고 국외의 매뉴얼 도구를 번역하여 사용하는 방법은 도구 번역에 대한 국제 지침이 지켜지지 않고 문화적 차이로 인해 사용이 제한적이다. ${ }^{16,17}$ 본 연구는 이러한 배경에서 컴퓨터 기반의 접근성 평 가도구인 CAP을 설계 구현하였고, 타당도와 신뢰도를 검증하고자 실 시하였다. 컴퓨터 입력장치 사용을 위한 필수적인 능력과 기능적 상 호작용을 측정할 수 있는 시스템을 개발하려면 관련 문헌을 고찰하 고 가장 보편적으로 행해지는 상호작용 요소와 과제를 분석해야 한 다.18 따라서 본 연구서도 관련 분야의 다양한 문헌 고찰과 평가도구 분석, 기초적인 입력장치 조작에 관한 과제분석, 그리고 전문가 자문 및 임상 유용성 평가를 통해 개발과 수정이 반복적으로 이루어졌다.

컴퓨터 접근성 평가에 있어 속도, 정확도, 그리고 효율은 운동 능력 에 대한 지표이자 입력장치 조작 능력을 평가하는 방법이다. 효율은 커서가 이동하는 동안의 안정성을 말하며, 커서의 이동 궤적과 이동 흔적의 부드러움을 탐지하는 것이다. ${ }^{19} \mathrm{CAP}$ 은 이러한 모든 변수를 측 정할 수 있도록 설계하여 정량적 측정은 물론 정성적 측정이 가능한 장점이 있다. 또한 컴퓨터 기반 평가도구는 사용자의 요구에 부합하 는 기능 검사를 맞춤 계획할 수 있어야 한다. 즉 화면의 물체 크기와 색상, 과제의 인지적 복잡성 등을 말한다. 또한 기능 검사는 연속적인 프레젠테이션이 유사하여 이전의 수행력과 비교할 수 있어야 하나 검사 내용이 학습되지 않도록 동일하지 않게 설계되어야 한다. ${ }^{20} \mathrm{CAP}$ 역시 이들 요인을 고려하여 설계 구현하였고' resource' 파일에 직접 평 가자가 수행 과제를 등록, 삭제할 수 있도록 엔진 튜닝이 가능한 유연 한 구조를 가졌다. 예를 들면, 문자입력 검사시 평가자가 직접 사용자 의 수준에 맞는 문장을 선별하여 등록할 수 있다. 포인팅 검사를 위 한 표적물은 단순한 사각형이나 원형 형태뿐만 아니라 아이들이 좋 아하는 '뽀로로' 이미지나 특정 이미지를 등록하여 사용할 수 있으므 로 평가 및 훈련에 대한 흥미와 동기부여를 높여줄 수 있도록 하였다. 그리고 과제수행의 난이도를 수직적 구조로 구성하여 다양한 기능 수준에 맞게 조정할수 있다.

지난 수십 년 동안 컴퓨터 기술의 발전과 함께 측정 및 평가 현장 에서 컴퓨터 기반 검사가 뚜렷한 증가를 보이고 있다. 특히 컴퓨터 접 근성 평가는 직접적인 컴퓨터와의 상호작용을 통해 검사가 수행되는 전산화 기반 평가도구가 신뢰도를 높일 수 있다. 장애인의 운동능력 이나 기능을 평가하기 위해 전산화된 측정을 통해 이미 개발된 측정 방법과 평가 과정을 체계화 할 수 있고, 기존의 측정방법들과 동질성 을 갖는지의 검증을 거쳐 표준화 자료를 구축할 수도 있다. ${ }^{21}$ 따라서 평가도구가 개발될 때에는 평가목적에 부합한지의 타당도와 신뢰도
가 검증되어야 한다. 본 연구에서는 105 명의 일반 대학생과 함께 16 명 의 지체장애학생을 대상으로 검사-재검사 신뢰도와 내적 일관성 신 뢰도를 알아보았다. 이들 신뢰도는 지체장애인의 평가를 위해 검사 도구가 활용되는 경우 중요한 정보를 제공한다. 검사-재검사 신뢰도 는 연속적인 기능 검사 수행 시 사용자 점수가 얼마나 일치하는지를 보여주는 것으로, 연속적인 순서 효과로 나타나는 변화를 이해할 수 있기 때문에 연속적인 CAP 검사를 통해 데이터를 더 잘 이해할수 있 다. 내적 일관성 신뢰도는 검사항목 사이의 유사성 또는 측정의 일치 도를 추정하는 방법으로 사용자의 컴퓨터 입력 기술이 각기 다르기 때문에 개별 사용자의 CAP 점수가 다른지 여부를 알려준다.22 연구 결과 검사-재검사자료의 상관계수는 일반 대학생의 경우 $r=.82$ 로 높 은 신뢰도를 보였고, 영어 문자입력(r=.69)을 제외한 모든 검사항목에 서 0.7 이상의 신뢰할만한 수준을 보였다. 지체장애학생의 경우에는 $\mathrm{r}=.86$ 으로 좀 더 높은 신뢰도를 보여 스캐닝 $(\mathrm{r}=.68)$ 을 제외한 모든 검 사항목에서 높은 검사-재검사 신뢰도 기준인 0.8 이상을 나타냈다. 이 는 15 명의 장애인을 대상으로 Compass 프로그램의 검사-재검사 신 뢰도를 연구한 Koester 등 15 의 연구와 유사한 결과였다. 내적 일관성 신뢰도 검증 결과 Cronbach $a$ 값은 일반 대학생의 경우 0.63 으로 중등 도의 신뢰도 수준을 보였으나 지체장애학생은 0.79 로 높게 나타났다. Cronbach $\alpha$ 값은 구성을 이루는 단일성을 측정하는 변수 설정이 얼마 나잘 되었는가를 측정하는 것이다. 본 연구에서 관찰된 중등도의 높 은 $\alpha$ 값은 $\mathrm{CAP}$ 검사항목이 전반적인 컴퓨터 사용 기술을 측정하는데 적합하다는 의미이다. 그러나 각 검사가 독립된 기능을 측정하기 때 문에 매우 높은 일치성을 예측하기는 힘들었다. $\alpha$ 값이 더 높게 측정 되지 않은 이유가 바로 이 때문이다. Compass 프로그램의 내적 일관 성을 측정한 Koester 등 ${ }^{15}$ 도 $\alpha$ 값은 0.6 에서 0.8 사이가 이상적이고, 이 는 검사항목이 불필요한 중복 없이 전반적인 컴퓨터 입력기능을 검 사하기 때문이라고 하였다.

장애인을 대상으로 한 연구는 비장애인을 대상으로 한 연구와 달 리 대상자 표집에 한계가 있다. 따라서 특정 장애유형의 인원과 분포 특성을 고려하여 피험자의 특성과의 관계를 상관분석이나 집단차이 분석으로 알아보아도 무관하다. ${ }^{21}$ 이는 사전에 집단 간 차이를 논리 적으로 예상하고, 실제로 수집된 자료에서 예상된 방향으로 집단 간 에 차이가 나타난다면 타당도의 증거로 해석할 수 있기 때문이다. 타 당도를 확인하기 위해 내적 구조 검토와 외적 관계 검토를 실시해야 하는데 내적 구조의 검토는 관찰된 변인들 간의 내적 관계를 알아보 기 위한 것으로 구성 타당도를 통해 검증된다. 즉 검사의 구인을 정확 하게 측정하고 있고, 가능한 가장 정확한 준거 검사 도구를 이용하는 것이 중요하다. ${ }^{23}$ Compass는 구성타당도 측정을 통해 컴퓨터에서 문 자입력과 포인팅기기 사용, 그리고 스위치 작업 수행 등 기능 검사를 이루는 요인 구성을 확인하였다. 본 연구에서 설계 구현한 CAP은 
Compass 검사항목을 참고하였기에 구성타당도 검증은 생략하였고, Compass 프로그램과의 상관관계를 분석하여 공인 타당도를 검증하 고자 하였다. 그 결과 포인팅과 스캐닝, 그리고 문자입력 검사에서 모 두 통계적으로 유의한 상관관계를 보였다. 또한 CAP의 수렴타당도를 알아보기 위한 하위 검사항목 간 상관계수도 통계적으로 유의하게 나타났다. 이론적으로 수렴타당도를 측정하는 직접적인 방법은 같 은 특성을 다른 방법으로 측정했을 때 그 방법간의 상관계수를 산출 하여 구하게 된다. 그러나 본 연구에서는 컴퓨터 접근성의 다면적 특 성을 포인팅과 스캐닝, 그리고 문자입력이라는 각기 다른 방법으로 측정하였기에 통계적 유의성에도 불구하고 상관계수가 높게 나타나 지 않았다. 즉 스캐닝 기술과 문자입력 또는 포인팅 기술이 갖는 과제 수행의 특성 차이로 인해 각 하위 항목간의 상관계수가 낮게 나타났 다고 사료된다.

결론적으로 논의한 바와 같이 본 연구에서 설계 구현한 CAP은 타 당도와 신뢰도가 입증되어 지체장애인의 컴퓨터 접근성을 평가하는 도구로 적합하다고 판단된다. 따라서 컴퓨터 입력장치를 사용한 과 제 수행력의 명확한 양적 정보를 얻을 수 있어, 전문가는 이러한 양적 정보를 해석함으로써 사용자의 컴퓨터 접근성 문제를 증명할 수 있 고 이를 해결할 수 있는 구체적 해결방안을 제시할 수 있을 것이다. 예를 들어, 불수의운동으로 소 근육 운동조절에 어려움이 있는 사용 자가 일반키보드보다 확대키보드를 사용했을 때 입력 정확도 및 속 도가 향상되었다는 CAP 데이터가 확보된다면 확대키보드를 추천하 여 컴퓨터 접근성을 향상시킬 수 있음을 의미한다. 또한 사용 가능한 다양한 인터페이스의 예측 수행력을 비교할 수 있고, 훈련 중재 계획 을 수립할 수 있음은 물론 시간 경과에 따른 사용자의 능력 변화 및 중재 효과를 측정할 수 있을 것이다. 그러나 지체장애인의 컴퓨터 접 근성에 영향을 미치는 요인은 $\mathrm{CAP}$ 를 통해 얻을 수 있는 양적 정보 외 에 다양한 변수가 작용하므로 이들 요인을 고려한 서비스 중재가 요 구되며, 정량적 데이터와 함께 컴퓨터 사용에 영향을 미칠 수 있는 작 업환경 같은 외적 요인들을 반영한 연구도 필요하다고 생각한다.

\section{ACKNOWLEDGEMENTS}

This research was supported by the Korea Nazarene University research grants 2014 .

\section{REFERENCES}

1. Burton M, Nieuwenhuijsen ER, Epstein MJ. Computer-related assistive technology: Satisfaction and experiences among users with disabilities. Assist Tech. 2008;20(2):99-106.

2. Dumont C, Vincent C, Mazer B. Development of a standardized instru- ment to assess computer task performance. Am J Occup Ther. 2002; 56(1):60-8

3. Burkhead EJ, Sampson JP, MeMahon BT. The liberation of disabled person in a technological society: access to computer technology. Rehabil Lite. 1986;47:162-8.

4. Rhee KM, Kim IS. A study on improving computer accessibility through alternative access and establishing a model for computer education room for children with physical disabilities. The Edu Jl Phys Mult Disabil. 2004;43:161-79.

5. Jeong, DH. Effect of biomechanical intervention based on custom seating system on activities of mouse click for children with cerebral palsy. 2012;24(2):57-65.

6. Simpson R, Koester HH, LoPresti E. Research in computer access assessment and intervention. Phys Med Rehabil Clin N Am. 2010;21(1): 15-32.

7. Kim DI, Kim KS, Jeong SL, et al. Learning experience of students participating in course-based assistive technology development. J Special Edu \& Rehabili Sci. 2013;52(4):391-409.

8. Chen MC, Chu CN, Wu TF, et al. Computerized assessment approach for evaluating computer interaction performance. ICCHP 2006, Lecture Note Com Sci 4061. 2006:450-6.

9. Koester HH, McMillan WW. Software for assessing computer usage skill. Proceedings of RESNA '97 Annual Conference, Pittsburg, Arlington, VA: RESNA Press, 1997:78-86.

10. Koester HH, LoPresti EF, Simpson RC. Measurement validity for Compass assessment software. Proceedings of RESNA 2006 Annual Conference. Arlington, VA: RESNA Press, 2006:125-34.

11. Yook JH, Park KO. Construct validation of screening index on assistive devices of computer input for individuals with physical disabilities (SACIP). Kor J Special Edu. 2010;45(2):69-88.

12. Lee JH, Rhee KM. The development of software for computer access assessment of persons with cerebral palsy. Kor J Phys Multi Disabil. 2010; 53(1):83-103.

13. Yook JH, Kim JS, Oh HJ. Implementation of Korea-computer access assessment system (K-CAAS) for persons with physical disabilities. J Digit Cont Soc. 2012;13(3):335-42.

14. Kim KA, Jeong DH. A study on assistive technology for pediatric therapists. J Kor Phys Ther. 2013;25(1):1-9.

15. Koester HH, Simpson RC, Spaeth D, et al. Reliability and Validity of Compass Software for Access Assessment. Proceedings of RESNA 2007 Annual Conference, Phoenix, AZ. Arlington, VA: RESNA Press, 2007: 96-107.

16. Yoo SH, Ha HK, Lee HJ. Korean cultural adaptation of working alliance inventory and its reliability. J Kor Phys Ther. 2014;26(2):90-6.

17. Lee HJ, Song JM. Development of revised Korean version of ICF. J Kor Phys Ther. 2014;26(5):344-50.

18. Wu TF, Chen MC. Performance of different pointing devices on children with cerebral palsy. Universal Access in HCI, Part III, HCII 2007, Lecture Note Com Sci 4556. 2007:462-9.

19. Chen MC, Meng LF, Hsieh CF, et al. Computerized assessment tool for mouse operating proficiency. ICCHP 2004, Lecture Note Com Sci 3118. 2004:849-56.

20. Koester HH. Gathering and applying evidence in computer access services. Proceedings of AAATE 2009 Conference, Florence, RESNA Press, 


\section{TKPT $\begin{aligned} & \text { The Journal of } \\ & \text { Korean Physical Therapy }\end{aligned}$}

2009:234-41.

21. Jeong YT, Kim HC. Measurement for disability sport: Development, evaluation and application of examination devices. Kor J Phys Multi Disabil. 2008;51(4):19-39.

22. Yi SJ, Kim JS. Development of instrument for Korean osteoarthritis im-

\section{Dong-Hoon Jeong}

pact measurement scale (KAIMS) in hip and knee osteoarthritis. J Kor Phys Ther. 2014;26(2):82-9.

23. Lee MY. Criterion and convergent validity evidences of an accelerometer and a pedometer. The Kor J Meas Evalu Phys Edu Sport Sci. 2012;14(2): 1-13. 